\title{
NORMATIVIDADE CULTURAL E MARGINALIZAÇÃO DAS SEXUALIDADES: o preconceito no ambiente escolar contra a pessoa LGBT
}

\author{
Marilia Rocha Amando* \\ Iracema Campos Cusati** \\ Odair França de Carvalho***
}

RESUMO:Este estudo compartilha constatações evidenciadas na literatura sobre a normatividade cultural permeada por questões de gênero e sexualidade além de fomentar reflexão sobre propagação de diferença e discriminação a indivíduos considerados diferentes no ambiente escolar. Dentre as referências que embasam essa reflexão, destaca-se o livro "O corpo Educado: pedagogias da sexualidade", organizado por Guacira Lopes Louro propondo desvelar a relação entre práticas escolares, corpo e sexualidade. A revisão bibliográfica mostra que a intolerância em relação à homossexualidade na sociedade repercute na escola e que há demanda de políticas educacionais acerca da diversidade sexual visando o combate à homofobia.

Palavras-chave: Sexualidades; Gênero; Preconceito; Formação de Professores(as); Diversidade na escola.

\section{CULTURAL NORMATIVITY AND MARGINALIZATION OF SEXUALITIES:}

the prejudice in the school environment against the LGBT person

\begin{abstract}
This study shares findings evidenced in the literature on cultural normativity permeated by issues of gender and sexuality in addition to encouraging reflection on the spread of difference and discrimination to individuals considered different in the school environment. Among the references that base this reflection, we highlight the book "The Educated Body: pedagogies of sexuality", organized by Guacira Lopes Louro proposing to unveil the relationship between school practices, body and sexuality. The literature review shows that intolerance towards homosexuality in society has repercussions on the school and that there is demand for educational policies about sexual diversity with the aim of combating homophobia.
\end{abstract}

Keywords: Sexualities; Genre; Prejudice; Teacher Training; Diversity in school.

Submissão 30-06-19 Aceite 23-08-19

\section{INTRODUÇÃO}

Os temas "gênero e sexualidade" na contemporaneidade causam curiosidade e opiniões diversas, demandando cada vez mais a problematização sob a égide das práticas sociais e investigativas. Promover diálogos sobre questões como diversidade sexual e homofobia no ambiente escolar é crucial para provocar uma reflexão sobre as distinções e aproximações no que diz respeito às experiências vividas por sujeitos masculinos e femininos. Mais importante ainda é levar essas questões para o cotidiano escolar pois, nesse contexto há, diuturnamente, crianças e adolescentes convivendo com concepções, representações e questionamentos relacionados à temática em voga.

\footnotetext{
* Marília Rocha Amando é Graduada em Educação Física pela Universidade Federal do Vale do São Francisco (UNIVASF). Mestranda do Programa de Pós-graduação e Formação de Professores e Práticas Interdisciplinares (PPGFPPI), Universidade de Pernambuco (UPE). Membro do Grupo de Estudos e Pesquisas em História da Educação no Sertão do São Francisco (GEPHESF), Universidade de Pernambuco (UPE).

*** Doutora na área de Didática, Teorias de Ensino e Práticas Escolares pela Faculdade de Educação da USP (2013). Professora Adjunta do Colegiado de Matemática da Universidade de Pernambuco - UPE e Professora Permanente do Programa de Pós-Graduação em Formação de Professores e Práticas Interdisciplinares (PPGFPPI) - Mestrado Profissional, da Universidade de Pernambuco - Campus Petrolina.

**** Doutor pela Universidade Federal de Uberlândia - UFU. Professor Adjunto da Universidade de Pernambuco-UPE. Membro do colegiado de Pedagogia e Coordenador de Extensão da Universidade de Pernambuco.
} 
Na tentativa de propor uma reflexão sobre questões centrais concernentes à temática supracitada, esse artigo expõe aspectos que possivelmente fomentarão as discussões declaradas e almejadas pelos autores visitados. Primeiramente, é feita uma explanação sobre a normatividade cultural a respeito da sexualidade e suas imposições que causam intolerância e discriminação com o "ser" diferente. No segundo momento, é abordada a discriminação diante das diferenças e o preconceito sobre a diversidade sexual a partir da construção social heteronormativa que acaba causando uma marginalização das sexualidades. Na sequência, o terceiro ponto considerado, relata a escola como um espaço de propagação de diferença; o bullying contra crianças e adolescentes homossexuais que se faz presente nas escolas. E por último, o texto sinaliza acerca das concepções de professores sobre sexualidades interpenetrando as práticas escolares.

\section{NORMATIVIDADE CULTURAL A RESPEITO DAS SEXUALIDADES}

Frequentemente nos deparamos com pessoas nos dizendo como nos comportar, como e o que falar, como nos vestir, que caminho seguir para obter sucesso ou ser aceito em uma determinada situação. Tais conselhos de ordem refletem em todos os âmbitos de nossas vidas; no comportamental, na saúde (física, mental e qualidade de vida), na religião, na educação e até mesmo no campo afetivo (LOURO, 2008). O mundo está em constante transformação e algumas transformações sociais trouxeram com elas novas formas de relacionamento e estilos de vida que, segundo Louro (2011), desde a década de 1960 passaram a reivindicar seus espaços em esferas que, por muito tempo, eram consideradas imutáveis e universais.

Continuamente, por meio das ações culturais, foi determinado o que é natural; produziu-se e transformou-se a natureza e a biologia. Os corpos ganharam sentido socialmente por meio de uma definição de gênero, o "ser masculino" e o "ser feminino" e, para eles, determinou-se como e quais seriam as formas de expressão dos desejos e prazeres, além de uma codificação de possibilidades sexuais (LOURO, 2018).

Richard Parker (2018) afirma que a teoria da construção social ampara o argumento de que a sexualidade é construída de maneira diferente ao longo do tempo e pelas culturas. Deste modo, as identidades de gênero foram definidas pelas relações sociais e pautadas nas redes de poder de uma sociedade na qual as culturas fornecem divisões e rótulos diferentes para combinar experiências sexuais e de afeto. 
$\mathrm{Na}$ tentativa de entender qual a relação entre corpo e sexualidade, Jeffrey Weeks (2018) defende que, embora o corpo biológico seja o local da sexualidade, a sexualidade é mais do que puramente o corpo. Existem muitas maneiras de sentir o sexo. Inúmeras possibilidades de viver prazeres e desejos corporais que sempre são sugeridas, anunciadas e/ou promovidas socialmente (LOURO, 2018). Simone de Beauvoir (1980, pág. 9), em sua obra mitológica "O segundo sexo", afirmou, "não se nasce mulher: torna-se mulher". O que pensar a respeito de uma frase tão impactante, principalmente para a época em que foi lançada, final da década de 1940? Uma pequena revolução intelectual feminista se instalou e permanece até hoje.

Para burguesia que geralmente é a parte conservadora da sociedade, a emancipação da mulher é vista como um perigo que ameaça a moral e certos interesses (BEAUVOIR, 1980), pois a sexualidade representa extrema importância nas relações de poder entre homens e mulheres, entre pais e filhos, entre educadores e alunos, entre padres e não religiosos, entre a população em geral.

Foucault (1999) afirma que nas relações de poder, a sexualidade pode não ser o principal elemento, mas é utilizada no maior número de manobras e pode servir de ponto de apoio e de articulação às mais variadas estratégias.

Com o passar dos anos, discursos, ações e efeitos em prol dos movimentos dos direitos humanos atingiram as comunidades tradicionais, como a tão orgulhosa e convencional família brasileira; consolidam famílias compostas por casais heterossexuais, que possuem práticas e pensamentos que relacionam algumas dinâmicas de gênero e práticas sexuais de forma negativa, como no caso da pessoa LGBT, que é geralmente discriminada e excluída por julgamentos arcaicos.

Afinal, como relatou Michel Foucault (1999, p. 9),

Se for mesmo preciso dar lugar às sexualidades ilegítimas, que vão incomodar noutro lugar: que incomodem lá onde possam ser reinscritas, senão nos circuitos da produção, pelo menos nos do lucro. O rendez-vous e a casa de saúde serão tais lugares de tolerância: a prostituta, o cliente, o rufião, o psiquiatra e sua histérica.

Porém, é importante trazer um ponto chave a essa discussão. De acordo com Jeffrey Weeks (2018), os termos heterossexualidade e homossexualidade são relativamente recentes. A intenção era apenas definir a homossexualidade como forma distinta de sexualidade; entretanto, pessoas que faziam sexo com pessoas do mesmo sexo começaram a ser enquadradas como sodomitas ${ }^{1}$. A homossexualidade se tornou

\footnotetext{
${ }^{1} \mathrm{O}$ sodomita era visto como uma aberração temporária (WEEKS, 2018).
} 
uma identidade, uma forma de assujeitamento do indivíduo, como por exemplo, o louco. Logo, aqueles que eram os homossexuais começaram a alegar que a homossexualidade era algo diferente, que era marca de outros tipos de pessoas.

A heterossexualidade e a homossexualidade eram apenas classificações de pessoas que possuíam gostos sexuais diferentes. Entretanto, com o passar dos anos, a heterossexualidade foi se tornando norma. Foram criadas as regras, os padrões, uma estrutura de inteligibilidade social que condensa sentidos de normalidade à heterossexualidade e de anormalidade à homossexualidade. Antes havia sentidos de pecado, de errado; com a sexologia passou a ser doença, anormalidade. Ou seja, houve uma atualização do discurso religioso ao médico. Hoje, a discriminação, o preconceito e a intolerância existente contra as pessoas homossexuais, expõe um retrato de anos de discursos heteronormativos e da marginalização da homossexualidade, frutos dessa classificação entre o normal e anormal.

Além disso, de acordo com Louro (2018), é importante compreender que a sexualidade não é apenas uma questão pessoal, mas política e social. Desta maneira, a sexualidade é aprendida, construída de diferentes modos, por todos os sujeitos ao longo do tempo e das culturas.

Partindo do princípio de que a teoria da construção social sustenta o argumento de que a sexualidade é socialmente construída considerando tempo e culturas, Richard Parker (2018, p. 131-132) enfatiza que essa compreensão,

surgida nos últimos anos tem, então, redirecionado grande parte da
atenção da pesquisa antropológica e socióloga não apenas para os
sistemas sociais e culturais que modelam nossa experiência sexual, mas
também para as formas através das quais interpretamos e
compreendemos essa experiência.

Diante dessa afirmação e de toda a contextualidade acompanhada por ela, é necessário olhar para as manifestações culturais com sensibilidade. É preciso entender como os estilos se constroem e se reconstroem diante do arranjo de normalidade e diferença taxadas socialmente (LOURO, 2008), principalmente no âmbito da sexualidade. Além disso, é importante compreender que não existe uma fórmula única e válida para toda sociedade, sobre as manifestações do sexo. Não se pode reduzir o sexo a função reprodutiva, ao modo exclusivamente heterossexual; pois as pessoas pensam de maneiras diferentes, vivem em lugares desiguais, têm vidas com prioridades e satisfações distintas e são criadas por pessoas que pensam/agem de formas variadas. Sendo assim, é difícil determinar o que é normal, seja em uma cultura, seja de modo universal. 


\section{A CONSTRUÇÃO SOCIAL HETERONORMATIVA² E A MARGINALIZAÇÃO DAS SEXUALIDADES: A VIOLÊNCIA COMO RESPOSTA A VISIBILIDADE}

A sociedade brasileira, numa abordagem histórica, tem aceitado como norma o homem branco, heterossexual, cristão e de classe média. Partindo da obtenção dessa referência como identidade, todo o oposto, mulheres, pessoas que não sejam brancas, homossexuais, ou pessoas de outras religiões, é taxado como alternativo, problemático e/ou diferente (LOURO, 2011). Segundo Foucault (1999), a normalidade está entre as artes de julgar e é um princípio de comparação. A norma se propaga nas sugestões de comportamentos repetidos e observados no cotidiano, que servem como referência para todos (LOURO, 2008). Sendo assim, o que não estiver na norma, será considerado diferente.

Quanto a diferença, o problema não está apenas em considerar algo diferente, mas no que esse pré-julgamento acarreta. A discriminação, o preconceito, as variadas formas de violências físicas e psicológicas, a marginalização de alguém apenas porque esse alguém possui características e vontades próprias e divergentes das consideradas normais. Essa intolerância está bem descrita por Foucault (1999, p. 8):

O que não é regulado para a geração ou por ela transfigurado não possui eira, nem beira, nem lei. Nem verbo também. É ao mesmo tempo expulso, negado e reduzido ao silêncio. Não somente não existe, como não deve existir e à menor manifestação fá-lo-ão desaparecer - sejam atos ou palavras.

Trazendo o contexto para a dimensão do "ser homem" ou "ser mulher", ainda, a infância e adolescência, podemos afirmar que, socialmente, algumas características de diferença são rapidamente definidas entre meninos e meninas. De maneira geral, as meninas são compreendidas como mais delicadas, mais passivas, mais calmas. Já os meninos, são mais fortes, mais inquietos (WENETZ; STIGGER; MEYER, 2013). Até mesmo as preferências são classificadas; meninas preferem filmes românticos, enquanto os meninos preferem os filmes policiais, menina joga vôlei, menino futebol.

Embora essas demarcações de comportamento tenham sido passadas por gerações e reforçadas no ambiente escolar, é inquietante a forma como as pessoas lidam com aqueles que fogem a esse padrão. "Que instâncias e espaços sociais têm o poder

\footnotetext{
${ }^{2}$ Heteronormatividade: perspectiva que considera a heterossexualidade e os relacionamentos com pessoas de sexo diferente como fundamentais e naturais dentro da sociedade, levando por vezes à marginalização de orientações sexuais diferentes da heterossexual.
} 
de decidir e inscrever em nossos corpos as marcas e as normas que devem ser seguidas?", questiona Louro (2008, p. 18). Ainda segundo a autora, é fato que a maneira em que desfrutamos de nossos prazeres e vontades, desejos, jogos e parcerias, tal como a maneira que arquitetamos para colocar em prática nossos desejos, envolvem corpos, linguagens, rituais e gestos que são produzidos, marcados na cultura.

É durante a adolescência que passamos pelas experiências de conhecimento do nosso corpo, do nosso "eu", cujas vivências se desenvolvem dentro de quadros normativos. Geralmente as pessoas são rotuladas como homo ou heterossexuais durante a infância e/ou adolescência (TAQUETTE; RODRIGUES, 2015). É complicado assegurar que a existência biológica é único caminho a ser seguido pelos corpos. O gênero e a sexualidade são adotados única e exclusivamente pelo que julgam apenas descrever (PRADO; RIBEIRO, 2016). Porém, os corpos também são constituídos de cultura.

Para Judith Butler (1990), o sexo é o efeito e não a causa. Mais além que isso, é uma consequência repetitiva. Já o gênero é "a estilização repetida do corpo, um conjunto de atos repetidos no interior de um quadro regulatório altamente rígido que se cristaliza ao longo do tempo" (BUTLER, 1990, p. 33). As pessoas reproduzem as ações, comportamentos, falas e atos que são considerados normais para o gênero, reproduzem até que aparentem ser natural.

Muitas são as pessoas que nascem com uma estrutura genética feminina/masculina, mas não se reconhecem como mulher/homem. Além das meninas e meninos que preferem se relacionar sexualmente com pessoas do mesmo sexo. Estas pessoas são rapidamente rotuladas como a escória da sociedade, àqueles que não se encaixam, que estão fora da norma. Aliado a este rótulo está a discriminação e a exclusão dessas pessoas.

Os preceitos sociais da sexualidade começam na infância. A iniciação sexual como fator determinante na vida social de homens e mulheres, varia conforme a cultura e provoca, através das imposições, variadas formas de violência e repressão (LANZARINI, 2013). Partindo desse contexto, brotam as "algemas" e violências de gênero, como as práticas homossexuais que estão sempre associadas ao pecado, a transgressão moral, que motiva violência, estereótipos e causa medo desde a infância, fazendo com que homens e mulheres abram mão da sua real identidade sexual e sejam condenados ao armário $^{3}$.

\footnotetext{
${ }^{3}$ Armário: o comando de controle da sexualidade que domina e mantém a divisão binária hétero-homo da sociedade Ocidental desde o fim do século XIX (MISKOLCI, 2013).
} 
Na sociedade brasileira contemporânea, existem homens e mulheres que são socialmente heterossexuais, pois a qualquer deslize de caráter homossexual, são acusados de desvio de conduta. Tal desvio, de acordo com Goffman (1988), leva o sujeito a ser descrito como diferente dos outros membros do grupo social, pois vive uma vida distorcida da vida moral. Uma vida moral que é fortemente defendida e sustentada pelos outros membros. O medo ou preocupação com esse estigma acaba fazendo com que esses homens e mulheres façam uma constante busca pela invisibilidade social (LANZARINI, 2013), que pode ser facilmente encontrada em viagens, casas de show ou apartamentos fora dos seus ambientes de circuito social habitual, para que assim possam vivenciar seus desejos homossexuais mais íntimos que são frequentemente reprimidos na vida real, no cotidiano.

Firma-se então, diante desse medo social e preconceito interno, um fortalecimento do uso do armário, que reforça as relações por aparência, uma condição sexual de aparência e, muitas vezes, uma vida inteira de repressão e opressão. Além de colaborar com a discriminação em torno das relações homoafetivas, pois ao preferir se esconder por medo de uma repressão social, o indivíduo enfraquece o combate ao preconceito com pessoas que enfrentam a sociedade para viver as relações que deseja.

Como consequência do preconceito, as práticas de violência contra a pessoa LGBT só aumentam no Brasil. Um relatório apresentado pelo Grupo Gay da Bahia (GGB) apontou que no Brasil, apenas em 2017, 387 pessoas LGBT (lésbicas, gays, bissexuais, travestis e transexuais) foram assassinadas, e mais 58 pessoas cometeram suicídio. Em 2018 os números de suicídio aumentaram saltando de 58 para 100 casos. A pesquisa afirma ainda, que a cada vinte horas (20h) uma pessoa LGBT é brutalmente assassinada vítima da LGBTfobia. Esses dados fizeram do Brasil o país “campeão" mundial em crimes contra pessoas que não se consideram heterossexuais (GRUPO GAY DA BAHIA - GGB, 2017; GRUPO GAY DA BAHIA - BBG, 2018).

A tabela a seguir mostra uma estimativa do número de pessoas LGBT mortas no Brasil nos últimos dez anos. 


\section{PESSOAS LGBT MORTAS NO BRASIL POR ANO}

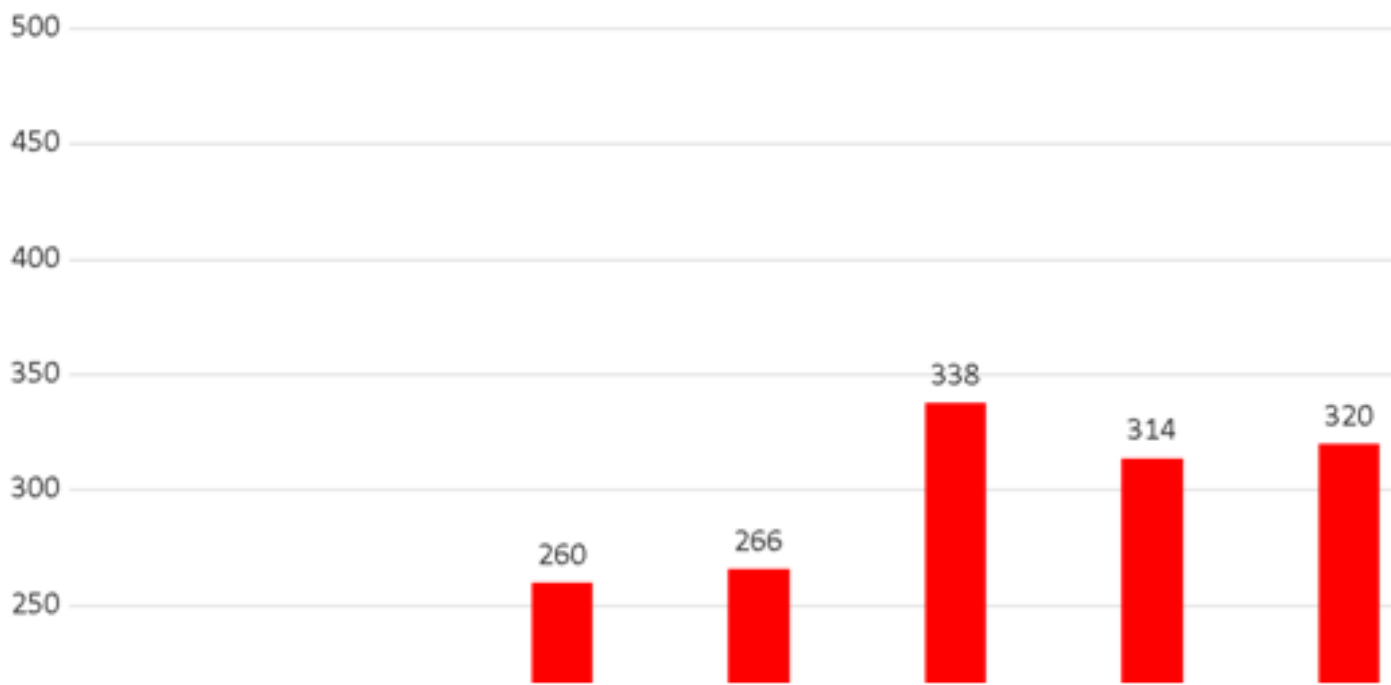

FONTE: Grupo Gay da Bahia - Relatório 2017

O número de mortes aumentou mais de $60 \%$ em menos de dez anos, saltando de 187 em 2008 para 445 em 2017. Além disso, apenas em menos de 25\% dos homicídios o criminoso foi identificado e em menos de $10 \%$ dos casos houve processo e punição dos assassinos (GRUPO GAY DA BAHIA - GGB, 2017). A impunidade faz crescer a violência.

De acordo com Madureira (2007), a homofobia possui um enraizamento afetivo que não deve ser ignorado. A autora afirma que quando existe um pequeno grau de proximidade entre duas pessoas, um heterossexual (que vive e reproduz com afinco a heteronormatividade) e um homossexual, assim que o heterossexual percebe a condição sexual do outro, uma barreira cultural é levantada. A partir do momento que essa barreira se torna mais forte, os sentimentos de desconforto aumentam e se expressam na vontade de eliminar o outro a partir desses sentimentos de desconforto.

Diante das facetas da homofobia, direitos básicos como respeito, educação e saúde, ficam fragilizados pelas diversas formas de discriminação da pessoa LGBT em meio à sociedade heteronormativa brasileira. Por sua vez, o Movimento LGBT ${ }^{4}$, que surgiu na década de 1970, vem lutando para combater a violência praticada contra essa população, reivindicando a criação de políticas púbicas e de legislações específicas que promovam uma melhor qualidade de vida e cidadania da pessoa LGBT.

\footnotetext{
${ }^{4}$ Movimento LGBT: Movimento social e político composto por sujeitos políticos - lésbicas, gays, bissexuais, travestis e transexuais - que lutam pelos direitos da livre orientação sexual e expressão das identidades de gênero.
} 
Além do movimento LGBT, existe a ABGLT (Associação Brasileira de Lésbicas, Gays, Bissexuais, Travestis e Transexuais), uma entidade de abrangência nacional, fundada em 31 de janeiro de 1995, sem fins lucrativos, que luta para defender e promover a cidadania da comunidade LGBT. A ABGLT tem atuação no campo internacional através do Conselho Econômico e Social da Organização das Nações Unidas.

A ABGLT participou diretamente da construção do programa Brasil Sem Homofobia ${ }^{5}$. Um programa do Governo Federal, que tem como objetivo a educação e a mudança de comportamento dos gestores públicos. Visando atitudes de firmeza e sinceridade, sem aceitar atos de discriminação. É um programa que se diz adotar o combate a violência como bandeira de luta. O programa Brasil sem Homofobia foi lançado em 2004 e desde então, junto a ABGLT, atua em avanços de políticas públicas em prol da comunidade LGBT.

Após muita luta, é possível afirmar que alguma coisa já mudou positivamente sobre a visibilidade e sobre os direitos da pessoa LGBT. Como o casamento entre pessoas do mesmo sexo, que é possível ser realizado no Brasil desde 14 de maio de 2013, sob a Resolução $n^{\circ}$ 175/2013 do Conselho Nacional de Justiça (CNJ) ${ }^{6}$. O então Ministro Joaquim Barbosa, assinou a decisão que continha como artigo primeiro o seguinte trecho: "É vedada às autoridades competentes a recusa a habilitação, celebração de casamento civil ou de conversão de união estável em casamento entre pessoas do mesmo sexo." No primeiro ano de vigor, a lei viabilizou 3.700 casamentos em todo o país.

Além disso, pode-se perceber certa visibilidade também na TV aberta. Como marcas que quebraram as barreiras do preconceito e colocaram em suas propagandas casais homoafetivos, como $\mathrm{O}$ Boticário $^{7}$ e Riachuelo ${ }^{8}$. Também é possível enxergar alguma visibilidade nas novelas nacionais, como o casal Samuel e Cido (casal homoafetivo) da novela “O outro lado do paraíso" exibida em 2017 na rede Globo.

\section{A ESCOLA COMO ESPAÇO DE PROPAGAÇÃO DAS DIFERENÇAS: O BULLYING COMO TEMA DE AULA}

Adolescentes homossexuais possuem maior vulnerabilidade à saúde, seja por fatores individuais, programáticos e/ou sociais; se cuidam menos, sofrem mais

\footnotetext{
${ }^{5}$ Disponível em http://bvsms.saude.gov.br/bvs/publicacoes/brasil_sem_homofobia.pdf. Acesso em: 16/10/2018.

${ }^{6}$ Disponível em http://www.cnj.jus.br/busca-atos-adm?documento=2504. Acesso em: 17/10/2018.

${ }^{7}$ Disponível em https://www.youtube.com/watch?v=p4b8BMnolDI. Acesso em: 17/10/2018.

${ }^{8}$ Disponível em https://www.youtube.com/watch?v=5p2nclMZ-UI. Acesso em: 17/10/2018.
} 
violência e geralmente se deparam com atendimentos no serviço de saúde que não levam em conta sua diversidade (TAQUETTE; RODRIGUES, 2015). O bullying (agressão física e/ou psicológica praticada por crianças e adolescentes, principalmente nas escolas, com o objetivo de causar dor ou desconforto) contra crianças e adolescentes homossexuais é-recorrente nas escolas. Atinge os jovens ao longo do seu desenvolvimento até a vida adulta, causando sofrimento. Pessoas que sofrem bullying na infância e adolescência tendem a entrar em depressão e podem chegar a abandonar a escola. É uma injúria moral com grave violação dos direitos humanos, além de ser um problema de saúde pública (CASTRO; ABRAMOVAY; SILVA, 2004).

Dentro desta perspectiva, e compreendendo que se tratando de civilização, pouco avanço nas concepções sobre corpo, alma e sexualidade foi percebido na sociedade brasileira (CUNHA; FURTADO, 2016), é imprescindível dialogar com a escola a respeito do desenvolvimento da sexualidade, visando um melhor entendimento sobre o cuidado em saúde mental, sexual e física de adolescentes homossexuais masculinos e femininos. Além disso, é perceptível que o ambiente escolar trabalha, muito significativamente, no aspecto heteronormativo, na compreensão de que o mundo é e deveria continuar a ser heterossexual (LOURO, 2011).

É na escola onde geralmente se concentra a maior parte da atividade de interação entre os jovens. Apesar disso, ela parece estar alheia a questões relacionadas à sexualidade dos alunos. Embora tenha nos Parâmetros Nacionais Curriculares um capítulo inteiro voltado para a orientação sexual, Farias (2015) afirma que as escolas preferem dar invisibilidade ao tema, descartando os estudos a respeito da temática e aparentemente preferem negar a existência de alunos homossexuais e de famílias homoafetivas.

É necessária a compreensão de que dar invisibilidade ao tema homossexualidade, já é considerada uma violência, pois tentemos imaginar o que é, para os estudantes gays e lésbicas, viver dentro do ambiente escolar tentando, a todo custo, esconder sua orientação sexual por medo de se tornar alvo de piadas e de sofrer retaliações.

Dinis (2011) relata que a homofobia na escola tem resultado na evasão escolar de estudantes que anunciam identidades sexuais e de gênero diferentes da norma heterossexual. Além de propiciar tentativas de suicídio de adolescentes em conflito com sua identidade sexual e de gênero, causadas pelos preconceitos e a discriminação sofrida no ambiente escolar. Teixeira-Filho e Rondini (2012) relataram a elevada taxa 
de suicídios entre jovens homossexuais. Nos Estados Unidos, cerca de um terço de todos os suicídios juvenis são cometidos por homossexuais.

Ainda de acordo com Teixeira-Filho e Rondini (2012), os estudos de gênero e LGBT, mostram que quando o jovem toma consciência da sua homossexualidade, ele passa por algumas fases. A primeira é a negação da sua atual condição, depois a raiva, a barganha ("farei de tudo para evitar isso. Vou compensar esse 'defeito' sendo o melhor..."), a depressão, e por fim, se as coisas correrem bem, a aceitação. A grande preocupação é se esse jovem não chegar à fase de aceitação, pois o que vem acontecendo é que durante a depressão alguns jovens acabam atentando contra a própria vida.

Borrillo (2000) afirma que, devido a toda contextualização histórica de superioridade masculina, os homens e as mulheres homossexuais, além de serem considerados fora da norma no padrão de normatividade da sociedade brasileira, ainda são vitimizados; os homens gays são igualados as mulheres como receptores do pênis, ou seja, colocados em situação de inferioridade. Já a mulher lésbica, por supostamente não gerar o filho do homem - aquela que seria a principal função da fêmea - é colocada ainda mais a margem da aceitação masculina, principalmente, por não possuir um pênis.

Teixeira-Filho e Rondini (2012) relatam algumas consequências do preconceito sofrido pela pessoa que se considera homossexual, como a negação da orientação sexual; as tentativas de mudar de orientação sexual; a sensação de nunca ser suficientemente bom; baixa autoestima, depressão, vergonha, raiva, ressentimento e sensação de negação com o próprio corpo; tendência a permanecer em um relacionamento abusivo ou em se tornar uma pessoa abusiva; tentativas de se passar por heterossexual, até mesmo casando-se com alguém do sexo oposto apenas para ganhar a aprovação da sociedade; tendências a realizar práticas sexuais não seguras e a realizar comportamento de risco; medo de ter intimidade, separação de amor e sexo; abuso de substâncias como drogas e álcool.

Além do exposto acima, o preconceito, seja ele da pessoa com ela mesma - pela não aceitação da sua condição sexual - ou vindo de terceiros, pode matar! Em 2018, 100 pessoas LGBT cometeram suicídio no Brasil (GRUPO GAY DA BAHIA, 2018). Os suicídios entre as pessoas que não se consideram heterossexuais acontecem principalmente porque esta pessoa se sente desacreditada, sem esperança e fora do contexto em uma sociedade que reforça as relações heteronormativas.

No Colorado, Oeste dos Estados Unidos, Jamel Myles, de apenas nove anos, suicidou-se (enforcando-se no próprio quarto) após sofrer bullying dos seus colegas 
de escola por assumir sua sexualidade. Nas férias escolares, o garoto contou para a família que era homossexual e que na volta às aulas contaria aos colegas sua orientação sexual. "Foi à escola e disse que ia contar às pessoas que era gay porque estava orgulhoso de si próprio”, disse Leila Pierce, mãe de Jamel. A mãe do garoto relatou ainda que o filho contou a irmã mais velha que os garotos da escola tinham falado para ele se matar. O caso ${ }^{9}$ aconteceu em Agosto de 2018.

No Brasil, são recorrentes os casos de hostilidade nas escolas com a pessoa LBGT. Em 2017, os resultados de um estudo realizado por Fernandes et al. (2017), revelaram que jovens homossexuais que vivenciaram variadas formas de violência na infância e início da juventude, sofreram repercussões negativas em suas relações interpessoais, autoconfiança, bem como no bem-estar pessoal e familiar. O estudo mostrou ainda, que as situações de constrangimento e humilhação sofridas, especialmente na escola, faziam os jovens sentirem-se desprotegidos e ameaçados no que diz respeito a segurança física e mental. O relato a seguir é de um dos entrevistados do estudo de Fernandes et al. (2017. p. 392):

Por volta da sexta série, começaram as gozações. Eu detestava os meninos. Só ficava brincando com as meninas e, na sala de aula, eu sempre ficava longe deles. Uma vez, eles me rodearam na saída da escola, dizendo que iriam me dar uma lição para eu aprender a ser homem. Meu coração acelera só de me lembrar. Por sorte, as meninas chamaram correndo a inspetora, e ela os separou e foi comigo até em casa, mesmo assim eles iam atrás de mim, me xingando. Quase parei de estudar por causa disso. Só não parei, porque minha avó não deixou de jeito nenhum.

O bullying é uma problemática frequente na área de educação. O processo de propagação de diferenças começa cedo, de maneira até imperceptível. A escola age com naturalidade em situações que nada tem de natural. A separação de meninos e meninas em grupos distintos nas brincadeiras, jogos, atividades, filas do lanche; separar os meninos das meninas é uma propagação de diferença. Como se eles não pudessem se envolver e desenvolver atividades nos mesmos grupos. Com base em errôneas concepções do que seria atividade de menino e atividade de menina, alguns educadores encontram dificuldades até nas escolhas dos esportes dos alunos.

Além das atividades escolares, Louro (2014) aponta como os livros didáticos simplesmente ignoram/negam a existência da diversidade, dos distintos arranjos de família, da pluralidade de atividades exercidas pelos sujeitos, pois trazem concepções

9 Disponível em https://exame.abril.com.br/mundo/menino-de-9-anos-se-suicida-nos-eua-apos-revelar-a-colegasque-era-gay/. Acesso em 31/08/2018. 
de dois mundos distintos; um mundo público e livre para o sujeito masculino e um mundo doméstico feminino. Além da representação de constituição familiar heteronormativa, onde a família é constituída por um pai, uma mãe e dois filhos (um menino e uma menina). As famílias homoafetivas simplesmente não existem dentro do universo escolar. Como a escola vai trabalhar a pluralidade, a diversidade e combater a homofobia escolar negando os sujeitos homossexuais, seu universo pessoal e seus familiares?

Nas escolas, as políticas de normalização colaboraram para que estudantes que contravenham aos ditos padrões - sejam eles referentes a gênero, religião, raça, sexualidade, constituição corporal ou estética - sofram com o preconceito, a exclusão ou auto exclusão do meio e de pessoas que realizam atos de chacota e discriminação (PRADO; RIBEIRO, 2016). A auto exclusão pode ser uma estratégia para não se visibilizar, pois quanto menos notada a pessoa for, menor o risco de sofrer com constrangimentos e insultos.

Guacira Lopes Louro (2018, p. 30) lembra que:

\begin{abstract}
A escola é, sem dúvida, um dos espaços mais difíceis para que alguém 'assuma' sua condição de homossexual ou bissexual. Com a suposição de que só pode haver um tipo de desejo sexual e que esse tipo - inato a todos - deve ter como alvo um indivíduo do sexo oposto, a escola nega e ignora a homossexualidade (provavelmente nega porque ignora) e, desta forma, oferece muito poucas oportunidades para que adolescentes ou adultos assumam, sem culpa ou vergonha, seus desejos. O lugar do conhecimento mantém-se, com relação à sexualidade, como o lugar do desconhecimento e da ignorância.
\end{abstract}

Diante deste contexto e na luta ao combate a homofobia dentro da escola, onde a gravidade não está presente apenas nas práticas de violência física, mas nas distintas manifestações de violência psicológica existente nos insultos e nas piadas, entre outras manifestações que violam direitos básicos e primordiais de um sujeito que é julgado inferior apenas por ser homossexual, é necessário que a escola reveja suas práticas visando uma atuação de forma respeitosa e responsável diante da sociedade contemporânea, pois possui essa responsabilidade por ser a instituição principal na construção do indivíduo como sujeito capaz exercer a cidadania. 


\section{EDUCAÇÃO SEXUAL NAS ESCOLAS: O PAPEL DO PROFESSOR X SUAS CONCEPÇÕES}

Diante de toda problematização e entendendo que a sexualidade dos adolescentes tem se manifestado de maneira acentuada dentro do ambiente escolar, além da consciência de que é fato que a homofobia existe na escola, ecoa pelos corredores e salas de aula, está presente nos livros didáticos e se alarga nos intervalos e nos banheiros; é imprescindível discutir sobre o papel dos professores e suas concepções a respeito da temática, pois a sexualidade é uma das questões que mais têm trazido dificuldades e desafios aos educadores dentro do ambiente escolar.

A partir da década de 1990, a escola e os professores que nela atuam, se tornaram responsáveis pelo desenvolvimento de ações pedagógicas voltadas a sexualidade, pois a temática, Orientação Sexual, foi estabelecida nos temas transversais dos Parâmetros Curriculares Nacionais (PCN's). O início da apresentação traz os seguintes objetivos: trabalhar o assunto buscando considerar a sexualidade como algo essencial à vida e à saúde; engloba as relações de gênero; o respeito com si e com o próximo em relação à diversidade de crenças, valores e expressões culturais existentes em nossa cultura; reforça a necessidade de prevenção de DST/AIDS e da gravidez indesejada durante a adolescência; além de diversas questões consideradas polêmicas.

Infelizmente, parece que essa responsabilidade ficou só no papel em muitas instituições de ensino. Na cidade de Petrolina-PE, por exemplo, discutir orientação sexual nas escolas do município está proibido por lei. Seria um problema de concepção ou só ignorância mesmo?

Olhando pelo lado da concepção e compreendendo que as pessoas têm visões diferentes, é importante entender que certas opiniões precisam ser colocadas em questão e que necessitam ser compreendidas e discutidas no campo da cultura e da transitoriedade (LOURO, 2011).

Discutir o tema homossexualidade com professores e professoras, por exemplo, pode não ser uma tarefa fácil, pois alguns podem ter concepções pautadas na heteronormatividade e/ou, podem estar amparados por alguma religião radical discriminatória. Ávila, Toneli e Andeló (2011), afirmam que os principais motivos que fazem com que professoras prefiram por não abordar o tema sexualidade na escola são, por acreditarem que falar a respeito pudesse despertar o interesse dos alunos, por crerem ser um assunto de família, e, em outros momentos, pelo isolamento do aluno devido ao medo de sofrer constrangimentos e/ou retaliações. 
Os professores e professoras não estão preparados para lidar com questões consideradas polêmicas, e/ou para assumir em sua jornada profissional uma postura ética no que se refere a educação sexual, orientação sexual e diversidade de gênero dos alunos, além das diversas expectativas e responsabilidades que recaem sobre as práticas docentes (ÁVILA; TONELI; ANDELÓ, 2011).

Para Farias (2015), é essencial a implementação de programas destinados à formação continuada de professores e de gestores que atuam na educação, visando discutir a diversidade familiar e questões relacionadas a gênero e sexualidade, no intuito de preparar tais profissionais para lidar com essas questões na prática escolar.

Como apontam autores que discutem a temática, cabe à educação atentar para o multiculturalismo, tanto como corpo teórico como campo político, que tem sido discutido em debates científicos na atualidade "pela necessidade de compreendermos a sociedade como constituída de identidades plurais, com base na diversidade de raças, gênero, classe social, padrões culturais, linguísticos e outros marcadores identitários" (GUERRA; CUSATI; COSTA, 2018, p. 158).

Além da necessidade de suplantar a falta de preparo em dialogar sobre homossexualidade, cabe à formação de professores estimular uma nova postura, que interpretada como posição ou atitude, permita olhar para o sujeito - tratado como diferente - com carinho e cuidado. Uma postura para tentar entender a posição desse sujeito e respeitar suas ações e condições. O professor e/ou professora deve se colocar à disposição para dialogar com seus alunos. De acordo com Deborah Britzman (2018), a escola tem uma cultura de ensino na qual o educativo está nos fatos e não na compreensão de questões íntimas, ou seja, com uma cultura de modos autoritários de interação social, fica difícil o diálogo, a possibilidade de novas questões, fazendo com que os professores e professoras não estimulem o desenvolvimento da curiosidade dos alunos.

A sexualidade é algo que cada indivíduo possui, pensa e vive de modo diferente do outro. Não há uma cartilha exata que ensine o adolescente o passo-a-passo de como agir, pensar e sentir o sexo. A sexualidade é intrínseca e extrínseca, ao mesmo tempo. É mutável, é instável, é pessoal. Eis então a dificuldade dos professores em falar sobre a orientação sexual em sala. Para Deborah Britzman (2018), o mais correto seria uma conversa franca, sem planejamento. Um diálogo aberto e livre entre professores e alunos, que poderiam leva-los a direções surpreendentes, fora desse contexto atual fechado e determinado no certo ou errado. Para que isso aconteça, é necessário que os professores e professoras também repensem suas próprias conceptualizações 
e representações sobre o sexo, para que assim, estejam abertos para explorações e curiosidades.

Ainda passeando pelas declarações de Deborah Britzman (2018, p. 109), a autora afirma:

Em primeiro lugar, as professoras e professores devem estar dispostos a estudar a postura de suas escolhas e a ver como essa postura pode impedir ou tornar possíveis diálogos com outros professores e com estudantes. As professoras precisam perguntar como seu conteúdo pedagógico afeta a curiosidade do/a estudante e sua relação com os/as estudantes.

Associada ao contexto acima, Souza, Silva e Santos (2015), relatam que as concepções e as representações acerca da heterossexualidade - que estão sendo compartilhadas e reproduzidas pelos professores no ambiente escolar - colaboram para que aconteçam variadas manifestações de violências contra a pessoa LGBT cotidianamente na escola. Os autores afirmam ainda, que as representações dos professores e professoras sobre a homofobia, estão consolidadas em diferentes normatizações que compõem a realidade social, e quando aceitas sem questionar ou problematizar, ajudam a fomentar preconceitos e discriminações contra a diversidade sexual.

Ávila, Toneli e Andaló (2011), após entrevista com três professoras que tinha em sua formação apenas o magistério, relataram que para elas, a homossexualidade dos alunos era a problemática, nas palavras das professoras, "mais difícil de lidar" quando o assunto era orientação sexual. Pois era preciso "lidar" com um assunto que, além da "sociedade não aprovar" e da religião das professoras considerar uma "abominação", era "uma escolha" que não "conseguiam aceitar $e$, com todo o respeito", não era possível "deixar de tentar ajudar a pessoa a mudar". O professor é um formador de opinião e como tal, deve estar atento e atualizado sobre questões que regem a vida dos seus alunos, levando em consideração a individualidade de cada um. Deve ser um aliado na tentativa de romper essa estrutura heteronormativa existente nas escolas. Como disse Paulo Freire (2006, p. 45):

É preciso que a educação esteja - em seu conteúdo, em seus programas e em seus métodos - adaptada ao fim que se persegue: permitir ao homem chegar a ser sujeito, construir-se como pessoa, transformar o mundo, estabelecer com os outros homens relações de reciprocidade, fazer a cultura e a história [...] uma educação que liberte, que não adapte, domestique ou subjugue.

Atualmente tem-se percebido uma consolidação de representações e concepções, pois os professores e professoras não são apenas responsáveis pela transmissão 
e construção do conhecimento. Além disso, eles também reproduzem nas escolas e salas de aula, padrões sociais, valores, concepções e idealizações, pois ao contrário do que se imagina, o(a) professor(a) não entra em sala deixando para traz suas raízes e manifestações. $\mathrm{O}$ (a) professor(a) é carregado(a) de representações, histórias e experiências de vida, que influenciam suas identidades e discursos; e tudo isso entra com ele(a) em sala.

Em junho de 2018, um professor de Medicina da Universidade de Rio Verde, surpreendeu seus alunos do quinto período de medicina ao colocar na prova uma questão com teor homofóbico. A questão tinha no enunciado: "Paciente Davi, de 24 anos, estava com abscesso na nádega e seu noivo serelepe, ao ver aquele quadro horroroso, ficou tresloucado e furou o abscesso com espinho de limoeiro em um movimento rodopiante de bailarino, imitando um beija-flor [...]”. A questão gerou desconforto entre alguns alunos que denunciaram o professor a reitoria da universidade. "Medicina é uma profissão a serviço da saúde da comunidade. Então, um professor elaborar uma questão desse cunho[...] Ele não tem que criar nenhum tipo de discriminação, independentemente da orientação da pessoa", disse um aluno. O professor acabou sendo exonerado do cargo $^{10}$.

A fim de evitar acontecimentos como o exposto acima, uma estratégia que deveria ser pensada, é através de investigações, tentar desconstruir concepções e representações que fundamentam preconceitos e estereótipos. É imprescindível que haja uma avaliação na formação dos profissionais da educação com relação às questões de gênero e sexualidade.

Os professores e professoras, aliados as instituições de ensino, devem estar atentos às mudanças globais da sociedade contemporânea. Devem iniciar processos de inovação e reformas nas pedagogias sobre a orientação sexual, na tentativa de dar conta dos desafios acerta da diversidade, pois a diversidade sexual e cultural (GUERRA; CUSATI; COSTA, 2018) existe, e não há mais espaço para omissão, intolerância, ignorância e homofobia.

\section{CONSIDERAÇÕES FINAIS}

Diante do exposto, foi possível perceber que as percepções com relação à homossexualidade e a estrutura heteronormativa impressa no ambiente escolar,

\footnotetext{
${ }^{10}$ Disponível em https://g1.globo.com/go/goias/noticia/professor-demitido-por-prova-com-teor-homofobico-diz-quenao-ve-nenhum-tipo-de-preconceito.ghtml. Acesso em 04/09/2018.
} 
têm influenciado fortemente o comportamento de professoras e professores. A falta de informação e a preferência em não refletir e discutir sobre o tema, repercute na invisibilidade da pessoa LGBT.

Percebendo que aceitar a existência de sexualidades diferentes da heterossexualidade é considerada uma ameaça a sociedade heteronormativa brasileira, podemos afirmar que o preconceito e a discriminação com a pessoa LGBT, é, portanto, um problema de aceitação das diferenças. Aceitar o diferente seria o mesmo que acabar com a hierarquia de grupos homogêneos que se enxergam superiores a algo ou alguém. Como o homem que se acha superior a mulher ou o heterossexual que se acha superior ao homossexual.

Portanto, a implantação da discussão sobre o tema orientação sexual, estabelecido nos temas transversais dos Parâmetros Curriculares Nacionais (PCN's), implica na difícil tarefa de aceitação de diferenças; diferenças estas, que foram construídas baseadas em crenças (principalmente religiosas) que devem ser desconstruídas, para que a sociedade possa tentar viver em uma condição de igualdade de direitos humanos, qualidade de vida e saúde psicológica.

É indispensável que a escola perceba a importância em dialogar sobre o tema, pois é no período escolar que crianças e adolescentes estão construindo a sua “identidade". É preciso que a escola tenha espaços que visem trabalhar a formação desses jovens, objetivando a construção de um sujeito capaz de refletir, valorizar e respeitar a diversidade cultural e sexual no seu meio social. Pois é evidente que a luta pela implantação de uma política educacional pela diversidade sexual e de combate à homofobia na escola, tem se mostrado extremamente árdua, difícil e atravessada por resistências heteronormativas.

Contudo, é urgente a implementação de políticas públicas eficientes que visem o fim da homofobia escolar, pois a cultura heteronormativa imposta pela sociedade brasileira impõe regras e seguimentos que ditam e limitam o que é certo e errado a respeito da sexualidade. A heteronormatividade assumida e reforçada na esfera escolar, favorece o desinteresse dos(as) professores(as) em buscar informações a respeito das sexualidades dissidentes. Informações essas que poderiam contribuir para a diminuição da homofobia escolar. 


\section{REFERÊNCIAS}

AVILA, André Heloy; Filgueiras e ANDALO. Professores/as diante da sexualidade-gênero no cotidiano escolar. Psicol. estud. [online]. 2011, vol. 16, n. 2, pp. 289-298. ISSN 1413-7372. Disponivel em: http://dx.doi.org/10.1590/S141373722011000200012. Acesso em: 10/04/2019.

BEAUVOIR, Simone. O segundo sexo. Rio de Janeiro: Nova Fronteira, 1980.

BORRILLO, Daniel. L'homophobie. Paris: Presses Universitaires de France, 2000.

BRITZMAN, Deborah. Curiosidades, sexualidade e currículo. In: LOURO, G. L. O corpo educado: pedagogias da sexualidade. 4. Ed.; Belo Horizonte: Autêntica, 2018, p. 105-142.

BUTLER, Judith. Fundamentos contingentes: o feminismo e a questão do pós-modernismo. Cadernos Pagu, n. 11, p. 11-42, 1990.

CASTRO, Mary Garcia; ABRAMOVAY, Mirian; SILVA, Lorena Bernadete da. Juventudes e sexualidade. Brasília: Unesco, 2004. Disponível em: http://www.cepac.org.br/agentesdacidadania/wp-content/uploads/2014/04/Unesco_ juventudes_sexualidade.pdf. Acesso em: 10/04/2019.

CUNHA, Marinalva Vitorino; FURTADO, Juliana Haetinger. Homofobia no contexto escolar de uma escola da zona rural no município de Porto Velho. Revista Igarapé, v. 1, n. 2, p. 97-111, 2016. Disponível em: http://www.periodicos.unir.br/index.php/ igarape/article/view/2048/1728. Acesso em: 10/04/2019.

DINIS, Nilson Fernandes. Homofobia e educação: quando a omissão também é signo de violência. Educar em Revista, n. 39, p. 39-50, abr, 2011. Disponível em: https://revistas.ufpr.br/educar/article/view/21410/14111. Acesso em: 10/04/2019.

FARIAS, Mariana de Oliveira. Famílias homoparentais e escola: reflexões e possibilidades. Revista Ibero-Americana de Estudos em Educação, v. 10, n. esp, 2015. Disponível em: https://periodicos.fclar.unesp.br/iberoamericana/article/view/ 8332/5640. Acesso em: 10/04/2019.

FERNANDES, Hugo; OLIVEIRA, Eleonora Menicucci; VENTURA, Renato Nabas; HORTA, Ana Lucia de Moraes; DASPETT, Celina. Violência e vulnerabilidade ao HIV/AIDS em jovens homossexuais e bissexuais. Acta Paul Enferm. v. 30, n. 4, p. 390-396, 2017. Disponível em: http://www.scielo.br/pdf/ape/v30n4/0103-2100-ape30-04-0390.pdf. Acesso em: 10/04/2019.

FREIRE, Paulo. \& SHOR, Ira, Medo e ousadia: o cotidiano do professor. 11 Ed. Rio de Janeiro: Paz e Terra, 2006.

FOUCAULT, Michel. História da sexualidade I: a vontade de saber. Ed. 13, Rio de Janeiro: Graal, 1999.

GOFFMAN, Erving. Estigma: Notas Sobre a Manipulação da Identidade Deteriorada. 4 Ed. Rio de Janeiro: LTC, 1988.

GRUPO GAY DA BAHIA (GGB). Relatório 2017: Assassinatos de LGBT no Brasil. Salvador. Disponível em: https://homofobiamata.files.wordpress.com/2017/12/relatorio2081.pdf. Acesso em: 10/04/2019.

GRUPO GAY DA BAHIA (GGB). Relatório 2018: Assassinatos de LGBT no Brasil. Salvador. Disponível em: https://homofobiamata.files.wordpress.com/2019/01/ relatorio-2018-1.pdf. Acesso em: 10/04/2019. 
GUERRA, Maria das Graças Gonçalves Vieira; CUSATI, Iracema Campos; COSTA, Kleber Ferreira. Por um currículo plural na perspectiva do multiculturalismo. Dialogia, São Paulo, n. 30, p. 157-168, set./dez. 2018. Disponível em: https://doi.org/ 10.5585/Dialogia.n30.8798. Acesso em: 10/04/2019.

JEFFREY, Weeks. O corpo e a sexualidade. In: LOURO, G.L. O corpo educado: pedagogias da sexualidade. Belo Horizonte: Autêntica, 2018, p. 43-104.

LANZARINI, Ricardo. A viagem libertadora: para além das fronteiras sociais da sexualidade. Rosa dos Ventos, v. 5, n. 4, p. 548-558, dez. 2013. Disponível em: http://www.ucs.br/etc/revistas/index.php/rosadosventos/article/view/2138. Acesso em: 10/04/2019.

LOURO, Guacira Lopes. Gênero e sexualidade: pedagogias contemporâneas. Pro-Posições, v. 19, n. 2(56), p. 17-23, 2008. Disponível em: http://www.scielo. br/pdf/pp/v19n2/a03v19n2.pdf. Acesso em: 10/04/2019.

LOURO, Guacira Lopes. Educação e docência: diversidade, gênero e sexualidade. Formação Docente, v. 3, n. 4, p. 62-70, 2011. Disponível em: https://revformacao docente.com.br/index.php/rbpfp/article/view/31. Acesso em: 10/04/2019.

LOURO, Guacira Lopes. Gênero, sexualidade e educação: uma perspectiva pós-estruturalista. 16. Ed. Petrópolis: Vozes, 2014.

LOURO, Guacira Lopes. O corpo educado: pedagogias da sexualidade. 4 Ed. Belo Horizonte, 2018.

MADUREIRA, Ana Flávia do Amaral. Gênero, sexualidade e diversidade na escola: a construção de uma cultura democrática. (Doutorado) - Instituto de Psicologia, Universidade de Brasília, 2007.

PRADO, Vagner Matias do; RIBEIRO, Arilda Inês Miranda. Escola, homossexualidades e homofobia: rememorando experiências na educação física escolar.

Reflexão e Ação, v. 24, n. 1, p. 97-114, 28 abr. 2016. Disponível em: http://cev.org.br/arquivo/biblioteca/4039811.pdf. Acesso em: 10/04/2019.

RICHARD, Parker. Cultura, economia política e construção social da sexualidade. In: LOURO, G. L. O corpo educado: pedagogias da sexualidade. Belo Horizonte: Autêntica, 2018, p. 157-190.

SOUZA, Elaine de Jesus; SILVA, Joilson Pereira da; SANTOS, Claudiene. Homofobia na Escola: As Representações de Educadores/as. Temas em Psicologia, v. 23, n. 3, p. 635-647, 2015. Disponível em: http://pepsic.bvsalud.org/pdf/tp/v23n3/v23n3a09.pdf. Acesso em: 10/04/2019.

TAQUETTE, Stella Regina; RODRIGUES, Adriana de Oliveira. Experiências homossexuais de adolescentes: considerações para o atendimento em saúde. Interface Comunicação, Saúde, Educação, v. 19, n. 55, p. 1181-91, dez. 2015. Disponível em: http://www.scielo.br/pdf/icse/v19n55/1807-5762-icse-1807-576220140504.pdf. Acesso em: 10/04/2019.

TEIXEIRA-FILHO, Fernando Silva; RONDINI, Carina Alexandra. Ideações e Tentativas de Suicídio em Adolescentes com Práticas Sexuais Hetero e Homoeróticas. Saúde Soc. v. 21, n. 3, p. 651-667, 2012. Disponível em: http://www.scielo. br/pdf/sausoc/v21n3/11.pdf. Acesso em: 10/04/2019.

WENETZ, Ileana; STIGGER, Marco Paulo; MEYER, Dadmar Estermann. As (des)construções de gênero e sexualidade no recreio escolar. Revista Brasileira de Educação Física e Esporte, v. 27, n. 1, p. 117-28, mar. 2013. Disponível em: http://www.scielo.br/scielo.php?script=sci_arttext\&pid=S1807-55092013000100012.

Acesso em: 10/04/2019. 